The symposium as a whole carries a clearly defined and urgent warning which is well supported by the evidence presented. Vegetation and animal populations in arctic lands are beautifully adapted as a delicately balanced whole to a very harsh environment. Exploitation of the animal populations by hunting, though sometimes regrettable in its insensitivity to their decline, has not caused losses that could not be reversed through international cooperation. But the exploitation of the mineral resources of the arctic and development of land communications causes damage of a different order of magnitude. Heavy vehicles, by destroying vegetation and compacting the humus, so alter the thermal conductivity of the ground that the heat balance is changed and melting of the permafrost is initiated. A single passage of a vehicle can start a process of irreversible thermal erosion, leading in a few years to the formation of gullies many feet in depth. The disposal of waste presents a special problem when all decomposition is prevented by low temperatures, and there are no bushes to cover up the heaps of discarded oil drums and other refuse. Bad habits which may pass in the temperate regions become intolerable in the arctic.

It seems proved beyond reasonable doubt that the land surfaces of the arctic are extremely vulnerable to many normal activities of modern man. The vegetation and animal life are at the limit of their tolerance and their survival depends on their precise adjustment to small scale features of the environment. A very slight change in this environment usually has quite disproportionate effects and may result in devastation. The exploitation of the arctic regions requires a thorough scientific analysis of these problems, if irreversible damage is not to become widespread.

C. D. Pigott

\section{Wright Preserved}

An Original Theory or New Hypothesis of the Universe, 1750. By Thomas Wright. A Facsimile Reprint together with the first publication of "A Theory of the Universe, 1734". Introduction and Transcription by Michael A. Hoskin. (History of Science Library: Primary Sources.) Pp. xxxvii $+178+31$ plates. (Macdonald: London; Elsevier: New York, February 1971.) $£ 10.00$.

THIS addition to the Elsevier History of Science Library is primarily a facsimile of Thomas Wright's $A n$ Original Theory of the Universe, which was published in 1750 and which made Wright famous as the first person to appreciate the true nature of the Milky Way; an effect resulting from the immersion of the solar system in a much greater star system. Generally, Wright is perhaps credited with rather more than his due measure of respect in this context, for he did not conceive the idea of our galaxy as a disk of stars, but rather preferred to explain the observations in terms of a "galaxy" made up of spherical shells of stars. This does not, however, detract from the historical importance of his work.

But if he has received more than his share of the credit for discovering the nature of our galaxy, Wright's more far reaching theories of the universe have tended to be overlooked, his name being firmly established on the basis of one great discovery, rather than receiving the more general acknowledgment which his widely ranging ideas merit. Notably, his speculation that "the endless Immensity is an unlimited Plenum of Creations not unlike the known Universe" comes close to the realization that the universe (in the modern sense) is populated by galaxies of which our own is an unremarkable individual example. Although the mystic and religious associations brought into his work prevented Wright from making this final theoretical step, his work is well worth the wide attention which this reproduction should bring to it.

Dr Michael Hoskin's excellent introduction adds considerably to the merit of the volume as a whole, setting the theory of Wright in its historical perspective, and providing a very complete account of how the ideas developed from their first primitive form. In this context, it is fascinating to read the first ever publication of Wright's "A Theory of the Universe", written in 1734, when the author was only 22 and had received little formal education in the subject in which his ideas became so prominent. There can be few scientific works which have waited for over two hundred years for publication; as late as 1898 this manuscript was purchased, together with the bulk of Wright's papers, by Newcastle Central Library for only $£ 3.00$. A bargain then, the belated publication of the work provides an added bonus now for purchasers of this volume.

Apart from its importance to the history of astronomy, this facsimile is a very high quality reproduction of the original, the proliferation of plates being remarkable for an eighteenth century work. As the beautiful original is now exceedingly rare, bibliophiles will certainly welcome this copy. Astronomers may be more interested in the opinion that "could we view Saturn thro' a Telescope capable of it, we should find his Rings no other than an infinite Number of lesser Planets, inferior to those we call his Satellites", while, having been shown in "Letter the Fourth" that the Sun lies at the centre of a family of planets and comets, they may well be prepared to answer the question of the likely content of space near other stars in the way Wright proposes-"'Your Answer, I think I may venture to say, would not be nothing; and methink's I already hear you say, Why Planets such as ours." JOHN GRIBBIN

\section{For Want of Iron}

Iron Deficiency: Pathogenesis, Clinical Aspects, Therapy. By L. Hallberg, H. G. Harwerth and A. Vannotti. Pp. Xi +628 +16 . (Academic: London and New York, December 1970.) $£ 6.00$; $\$ 18.50$.

IN 1963, a Ciba Symposium on "Iron Metabolism" was held in Aix-enProvence, and in due course the proceedings were published (Iron Metabolism, Springer-Verlag, Berlin, 1964). The fifty-eight participants gave an up to date account of the basic and clinical aspects of the subject. This newer publication is an account of the papers given at a similar symposium organized by Geigy in Arosa, Switzerland, in 1969. On this occasion there were seventy-six experts taking part, twelve of whom had attended the earlier meeting. In each instance, the discussion following the papers is published, and it is of considerable interest to see the extent of progress during six years. Fortunately, each book contains an index. All the papers in Iron Deficiency are in English. There are three sections which deal respectively with the "Pathogenesis", "Clinical Aspects" and "Therapy of Iron Deficiency", and the following 38 pages are taken up with an account of a panel discussion on "Iron Therapy in Clinical Practice".

This is an essential book for anyone working in this field of interest, the amount of knowledge that is contained in it being very considerable. As might be expected, all aspects of iron metabolism are dealt with in detail, including iron stores, biochemical functions, regulation of iron transport, factors affecting absorption, and the supply and utilization of food iron, together with requirements during growth and pregnancy, and menstrual and other losses. The discussions are of considerable interest, highlighting, as they do, current gaps in knowledge. This more basic material occupies about 400 pages. The clinical section includes accounts of the prevalence of anaemia in certain European countries, but the chief value of the publication lies in the earlier part of the book. The size, comprehensiveness and value of the chapters vary tremendously : the largest contribution, by H. C. Heinrich of Hamburg, deals with intestinal absorption of iron in man and extends through 80 very detailed pages 